\title{
The Governance Challenge within Socio-Technical Transition Processes: Public Bicycles and Smartphone-Based Bicycles in Guangzhou, China
}

\author{
Hongze $\operatorname{Tan}^{1}$ and Shengchen $\mathrm{Du}{ }^{2, *(D)}$ \\ 1 Department of Sociology, Nankai University, Tianjin 300350, China; tanhongze@nankai.edu.cn \\ 2 Department of Sociology, Tianjin University of Technology, Tianjin 300384, China \\ * Correspondence: shengchendu@email.tjut.edu.cn
}

Citation: Tan, H.; Du, S. The Governance Challenge within Socio-Technical Transition Processes: Public Bicycles and Smartphone-Based Bicycles in Guangzhou, China. Sustainability 2021, 13, 9447. https://doi.org/ $10.3390 /$ su13169447

Academic Editor: Harald A. Mieg

Received: 4 July 2021

Accepted: 19 August 2021

Published: 23 August 2021

Publisher's Note: MDPI stays neutral with regard to jurisdictional claims in published maps and institutional affiliations.

Copyright: (c) 2021 by the authors. Licensee MDPI, Basel, Switzerland. This article is an open access article distributed under the terms and conditions of the Creative Commons Attribution (CC BY) license (https:// creativecommons.org/licenses/by/ $4.0 /)$

\begin{abstract}
In urban China, utilitarian cycling plays a significant role in achieving sustainable mobility. Within this context, different kinds of sharing-bicycle programs equipped with new technologies/devices emerge and extend. By comparing two generations of them in Guangzhou (China), this paper explores how new technologies impact existing modes of mobility governance. First, the technical innovations, e.g., app-based bicycle locks and micro-GPS equipment, contribute to liberating emerging private companies from existing governmental regulations based on land control. Second, the adoption of these innovations not only contributes to the accumulation of cultural and symbolic capitals based on a fashionable lifestyle but also links bicycles to personal point-to-point travel data that could be translated to economic capital. Third, the discrepancy between the dispositions of the government and private companies regarding the innovations opens an opportunity for the quick extension of sharing bicycles, which brings both positive and negative consequences on citizens' daily travel and life. The absence of other civic actors in the decision-making process accelerates the negative consequences caused by the profit-driven fast extension of sharing bicycles and the governmental top-down governing logic. These findings provide academia with implications for understanding the impact of innovations on achieving sustainable mobility.
\end{abstract}

Keywords: socio-technical transition; governance challenge; public bicycles; smartphone-based sharing-bicycles

\section{Introduction}

Coming into the 21st century, the transportation sector in cities all over the world is challenged by congestion, air pollution, fossil fuel depletion, road safety risks, and other relevant problems [1]. In China, especially in large cities like Beijing, Shanghai, and Guangzhou, these mobility-relevant problems are even more serious compared with those in western countries. Against this background, the issue of how to promote and govern a transition toward sustainable urban mobility/transportation, i.e., a fundamental transformation towards a more sustainable and "green" urban transportation system, has received increasing attention both in the policy arena [2] and in social-science research [3,4].

In this context, it is not surprising that the managers of Chinese cities, as a once "Cycling Kingdom", re-discover the potential function and benefits of urban cycling in dealing with the transportation and environmental problems they are facing. That is the reason the central government and its officials constantly showed their pro-cycling attitude and plans through a series of formal and informal documents [5]. In the meantime, a series of technological innovations around bikes and relevant infrastructures were also implemented within the pro-cycling area to bring bicycles back to the city [6]. Among them, the series of innovations that enable the business of two kinds of rental (or say, "sharing") bicycles- "public bicycles" and "Smartphone-Based Sharing Bicycles" (SBSBs, hereafter) showed their importance as the business grew rapidly in China in the past several years. 
The former refers to the kind of rental bicycles with docks and/or stations, which are provided and operated by certain private or state-owned companies. SBSBs are different as they do not have fixed stations/docks and can be unlocked/locked and charged through certain mobile phone applications. For public bicycles, by the end of 2016, more than 400 cities and counties in China had been equipped with public bicycle systems, which have provided 750 million trips to users across the country [7]. By 2020, SBSBs have been put into operation in more than 360 cities across the country, with 19.45 million vehicles invested, and the average daily order volume of sharing bicycles exceeds 45.7 million [8].

The emergence and quick extension of the new modes of daily cycling quickly attracted academic attention. Scholars have conducted a series of studies on changes in various dimensions brought by public bicycles and SBSBs. For instance, their impacts on local citizens' mobility pattern and experience $[9,10]$, the symbolic and cultural meaning of the new and active traffic mode and its social influences [11-13], the effective methods to improve the efficiency and sustainability of certain programs [14-16], etc. Among all the changes brought by the new mobility, however, those that occurred in local mobility governance have not achieved enough academic attention. Moreover, as pointed by Lin and Spinney $[17,18]$, some of the only exceptions basically regard the new mobility, and new technologies that make it a reality, as the result of governance, rather than the influencing factors. To fill this gap, the aim of this article is to explore how new technologies in the field of daily mobility/transportation impact existing modes of governance. More specifically, our research question is how the adoption of new technologies in the cycling field challenges the existing local mobility governance mode in urban China. Through a case study on the transition process from public bicycles to SBSBs in Guangzhou, China, we analyze the new technology as an influential element, rather than the static outcome, within the process of governance and explore the changes brought by it.

The article is structured as follows: We start by summarising the conceptual framework for this research - socio-technical transition and the field approach-based on a brief review of the research conducted on public bicycles and sharing bicycles governance. Then, we present the data collection and methods of analysis in the following section. Section 4 shows our main findings. We conclude with a discussion of the relevance of our findings in relation to the literature on technological innovation governance and urban cycling development.

\section{Literature Review}

\subsection{Socio-Technical Transitions and the Relevant Governance}

A socio-technical transition is a set of processes that lead to a fundamental shift in the socio-technical system [1]. Specifically speaking, sectors such as energy supply, water supply, and transportation can be conceptualized as socio-technical systems [19-21]. Such systems include certain necessary elements, like involved actors (individuals and organized ones), institutions and material artifacts, and the knowledge of [22,23]. These elements rely on and interact with each other [24] and also jointly provide specific services/functions for society. Therefore, it is necessary to explore the change, including innovations, within the system as a whole and dynamic process [25], which calls for a relational and interactive study approach regarding technological innovation and the relevant governance transformation.

Socio-technical transitions differ from simple technological changes by not only including technological changes but also including the changes that emerged in actors' practices and institutional structures [4]. Therefore, this analytical approach treats existing sectors as complex and adaptive societal systems in which changes occur and evolve, and the changes themselves are dynamic and ongoing processes. Thus, the governance of the changes is also a reflexive, evolutionary, and ongoing process in which different involved actors interact (in different forms) with each other [26]. Over the past decades, there has been a burgeoning literature unpacking technological innovation systems and the transition of them [27-29]. One of the key concerns within this area is the changes brought by the 
emergence of certain technologies, especially the institutional and organizational ones [30]. In general, the isolated approach, like the omnipotence of market failures, is replaced by a more relative approach such as system failures [31].

To reach this kind of relative and systemic understanding of technological transition and governance, there is a pressing need to deeply explore the socio-political changes brought by the innovation and implication of certain technology around any public issue [32], especially how these technical changes challenge the existing governance system and logic and the relevant consequences. At a more conceptual level, it refers to the issue of power and politics in transformation and transition processes, which, however, has been relatively neglected by the existing literature in this area [23]. Therefore, detailed and in-depth research guided by a relative and dynamic facet concerned approach on how institutional structures are changed through the strategic interplay of different types of actors regarding the innovation and implementation of a certain technology is needed in this research area [33]. That is what the field approach can contribute to.

\subsection{The Field Approach and the Changes within a Field}

Although there are many variations/sub-approaches within the field approach, the basic idea is that "to think in terms of field is to think relationally" [34]. According to Bourdieu, the concept of a "field" refers to "a patterned system of objective forces (much in the manner of a magnetic field), a relational configuration endowed with a specific gravity which it imposes on all the objects and agents which enter it" [35]. The whole social world is treated as a space within which various actors occupy different (structured) positions according to the volume and form of the valued resources-namely, the capitalthey hold [36]. The relations between different actors within a field and how the actors modify/conserve their positions are the foci of the analyses. Besides "field", there are another two concepts highlighting the key concern of the approach: the first one is capital, which refers to the resources that are valuable and at stake in a specific field, and it is the medium through which positions are attained and struggles are organized. Another one is habitus. It refers to the strategy-generating principles that translate the structured/objective field relations into perceptions and actions, which enable the actors to orient their actions to various situations [37].

Change and conflicts-including other relevant aspects such as struggles and resistance-are key concerns in Bourdieu's analysis. The key concern is what and how changes are produced and re-produced within networked relations. According to Krause [38], there are three basic analytical dimensions: variation in field autonomy, variations of field autonomy, and variation in the field structure. The key point is that a field can be vulnerable to actors and elements from other fields. The ways that any given field is linked to other fields are the key concern of exploration [39]. Among various relational factors, the impact of technologies and devices on relational fields attracts more academic attention. For instance, the new data-based technology and journalism [40], the innovation of restaurant and gastronomy [41], and so on. The key point is to put technologies/innovations from other fields as an analytical object and to explore how they bring changes to the members within a certain field. In other words, to treat the impact of the "new" technologies on certain social and political relations based on the unequal distribution of resources. Therefore, the field approach enjoys the ability to simultaneously depict the relations between different involved actors around a certain issue, which contributes to our understanding of the changes that occurred in the urban cycling field in China.

\subsection{Public Bicycles, Smartphone-Based Sharing-Bicycles and the Governance of Them in China}

"Public bicycles" refer to the kind of rental bicycles with docks and/or stations, which are provided and operated by certain private or state-owned companies. It has grown rapidly in China since the Hangzhou government (Zhejiang Province) introduced them from European cities (The first public bicycle program in China emerged in Beijing in 2006. It was jointly operated by seven companies, but it failed quickly and made little 
impact. For more details, please refer to the webpage of "Public Bicycle in Beijing" http://bjggzxc.jtw.beijing.gov.cn/Home_index_1_1.html, accessed on 3 August 2021), especially Paris. "Smartphone-Based Sharing-Bicycles" are different from public bicycles in that they do not have bicycle stations and can be unlocked/locked and charged through a mobile phone app (Table 1). This kind of "sharing bicycles" emerged in China in late 2015, and, as mentioned above, rapidly grew in many large Chinese cities in the past five years.

Table 1. Comparisons between public bicycles and Smartphone-Based Sharing-Bicycles ${ }^{1}$.

\begin{tabular}{cc}
\hline Public Bicycles \\
\hline Subjects of operation & $\begin{array}{c}\text { Mainly state-owned companies or governmentally } \\
\text { funded firms. }\end{array}$ \\
Users' qualification & $\begin{array}{r}\text { Having an urban public transport card and /or } \\
\text { paying a deposit [200-300 yuan]. }\end{array}$ \\
Price & Step charging, generally free for the first hour.
\end{tabular}

How to get a bike Going to fixed locations to rent bikes from stations.

Private companies, especially Internet companies.

Having a smartphone with the corresponding app installed, turning on GPS function, and paying a deposit [99-299 yuan]. Some SBSBs do not require a deposit.

Step charging, generally 1 to 1.5 yuan for the first 15 to $30 \mathrm{~min}$ [or, 2 to 3 yuan for the first one hour] Searching for nearby bicycles through the installed app, then going to the nearest one and renting the bike through the app.

In principle, any public area.

How to return the bike

Putting the bike back to a station with free parking space.

Payment method
Through the urban public transport card [or pay in cash in some cases].

1 The source: the authors' experience and observation during the fieldwork, and the "Bicycle Data" collected by Institute for Transportation and Development Policy, refer to http:/ / www.itdp-china.org/bikesharing/index/?lang=1, accessed 4 August 2021. The table is made by the authors.

The rapid development of public bicycles and SBSBs provides new flexible and "green" choices for urban residents' daily travel [42]. They, however, also bring about certain negative consequences, like the occupation of public spaces, the road-safety risks, and so on [18], which call for the necessary governance of them [10]. Therefore, the emergence and transition of public bicycles and SBSBs is a representative case of how certain technological innovations (and the implementation of them) challenge the existing governance logic and system around a public issue [11], and how the manager-the government-reacts to the change and challenge [43].

Although the number of studies in this field is growing rapidly, the research focusing on local mobility governance calls for more academic attention [15]. For now, existing studies in this direction generally focused on the decision-making and implementation processes of relevant local policies [44], the "failure of the market" regarding the SBSBs issue [45], and some other specific issues (like relevant legal matters and the division of responsibilities) of public bicycles and SBSBs [46]. These studies are insightful in exploring the failures/success of cycling governance. They, however, basically treat the new bicycles and the new system as the outcome of governance [17], as static elements outside the change process. According to the field approach mentioned above, however, the new kinds of bicycles, and the information and communications technology (ICT) technologies/devices installed on them [9], are in fact a kind of influential factor. Along with their emergence and extension, the social relations between existing actors within the cycling field in a city will change accordingly. In this article, we aim to help fill this knowledge gap with a study of the transition from public bicycles to SBSBs in Guangzhou, China.

\section{Methodology}

Guangzhou is the capital and the largest city in Guangdong Province in south-eastern China. At the moment, it is the third-largest Chinese city, behind Beijing and Shanghai, and it holds sub-provincial administrative status [47]. In 2015, the residential population within Guangzhou's administrative area was more than 13.5 million [48]. The role of urban cycling 
in Guangzhou's transportation system has experienced great change over the last three to four decades. Urban cycling in this city experienced a "promotion-reduction-repromotion" process [49]. Both public bicycles and SMSBs emerged and developed in the "repromotion" phase, which started in the first decade in the new century.

In this research, we adopted a qualitative case study approach to address the research questions because of its advantage in analyzing meanings, ideas, and changes over a relatively long period [50]. The data used in this paper stem from both documents and interviewees. In the first phase, we collected the existing documents and conducted a qualitative textual analysis [51]. The collected documents fit within five categories: the documents issued by the central government; the documents issued by the local government; the documents issued by the Guangdong Provincial Government and some national documents focusing on the regional development of the Pearl River Delta, where Guangzhou is located; and the documents issued or collected by pro-cycling NGOs (or semi-organized groups) in Guangzhou. In total, 61 relevant documents were collected for analysis. The analysis process consists of three rounds of text analysis focusing on three analytical categories: (1) Timeline: we coded all the information related to time (dates) in all documents to form a timeline framework; (2) Actors and Actions Categories: we distinguish three categories of involved actors: the government (central-regional-local), the market subjects [state-owned/private] and social actors (organized/unorganized) and sort out the actions of each type of subject according to the timeline; (3) Relations and Interactions Categories: we pick out the actions regarding more than one category of actors and preliminarily describe the relationship between different subjects.

Based on the qualitative text analysis, we further conducted semi-structured interviews and group discussions to obtain fruitful and in-depth data. From October 2016 to April 2017, we talked to more than 60 respondents through semi-structured interviews and focus group discussions. As the focus of this research is on governance changes, we conducted open-ended interviews guided by three basic questions/themes: (1) What has been different since public bicycles occurred? (2) What is the difference between public bicycles and SBSBs? (3) What has been different since SBSBs occur and extend? For different interviewees, the operationalization of the "what" in three questions is different but basically consists of four dimensions: daily mobility pattern and experience, the relationship and interaction among various actors (especially with the government), business model, and profit (mainly for managers of the cycling companies), attitude towards public bicycles and SBSBs. These questions and dimensions, however, are mainly a basic and open-ended guide for the interviewers' reference, and our basic logic is to follow the narrative logic of the respondents (In fact, compared with the passive title of "respondent" /"interviewee", we prefer to use the active title of "narrator" to refer to these information providers. However, in order not to confuse readers, we still use this title for the time being). According to the representativeness and effectiveness of the answers and eliminating duplicate information, we selected 25 interviewees as key ones. Table 2 shows the details of the key respondents. 
Table 2. List of Key Respondents.

\begin{tabular}{|c|c|c|}
\hline Code & Identity & Meeting Date \\
\hline GZ_01 & The leader of a pro-cycling NGO (BIKE-GZ) in Guangzhou & $\begin{array}{c}15 \text { October } 2015 \\
3 \text { February } 2016 \\
19 \text { April } 2016 \\
26 \text { March } 2017\end{array}$ \\
\hline GZ_02 & A member of BIKE-GZ in Guangzhou & 25 April 2016 \\
\hline GZ_03 & The leader of a cycling advocacy group in Guangzhou & $\begin{array}{l}2 \text { February } 2016 \\
25 \text { April } 2016\end{array}$ \\
\hline GZ_04 & The manager of a public bicycle enterprise in Guangzhou & $\begin{array}{l}23 \text { November } 2015 \\
25 \text { April } 2015\end{array}$ \\
\hline GZ_05 & The manager of a state-owned public bicycle enterprise in Guangzhou & 20 April 2016 \\
\hline GZ_06 & $\begin{array}{c}\text { An engineer from Guangzhou Urban Planning \& Design Survey Research Institute and } \\
\text { Transport Planning \& Design Studio }\end{array}$ & 20 April 2016 \\
\hline GZ_07 & A professor of urban planning and member of the Guangzhou government's think tank & 28 November 2015 \\
\hline GZ_08 & An academic researcher on urban cycling and public bicycle programs in China & 26 November 2015 \\
\hline GZ_09 & $\begin{array}{c}\text { An administrative staff member from Guangzhou Modern BRT and Sustainable Transport } \\
\text { Institute }\end{array}$ & $\begin{array}{l}20 \text { April } 2016 \\
27 \text { April } 2016\end{array}$ \\
\hline GZ_10 & A traffic policeman in Guangzhou & 2 April 2016 \\
\hline GZ_11 & The owner of a local bicycle shop & 16 July $2015^{1}$ \\
\hline GZ_12 & A bicycle seller and daily cyclist & $\begin{array}{l}2 \text { February } 2016 \\
2 \text { April } 2016\end{array}$ \\
\hline GZ_13 & A CPPCC member from Guangdong Province & 20 April 2016 \\
\hline GZ_14 & A bicycle repair man and member of a voluntary bicycle service group & 2 February 2016 \\
\hline GZ_15 & A junior civil servant in Guangzhou's transport department & 25 April 2016 \\
\hline GZ_16 & A manager of Guangzhou City Investment Property Management Co., Ltd. & March $2016^{2}$ \\
\hline GZ_17 & A cyclist who knows a lot about the Flower City Square case & 25 April 2016 \\
\hline GZ_18 & An urban transport expert in a governmental research institute & 5 February 2016 \\
\hline GZ_19 & A local resident and cyclist & 2 March 2016 \\
\hline GZ_20 & A local resident, daily cyclist, and local bicycle shop owner & 2 March 2016 \\
\hline GZ_21 & A local bicycle commuter & 15 April 2016 \\
\hline GZ_22 & $\begin{array}{c}\text { A local daily cyclist and member of the Guangzhou Youth Volunteer Association Bicycle } \\
\text { Service Corps }\end{array}$ & 16 April 2016 \\
\hline GZ_23 & The president of one of the largest public bicycle suppliers in China & 19 November 2016 \\
\hline GZ_24 & A media personage, cyclist, and blogger on WeChat & 19 November 2016 \\
\hline GZ_25 & A senior planner/official in a central research institute in China & 19 November 2016 \\
\hline
\end{tabular}

${ }^{1}$ This interview was conducted by a friend of the authors in Guangzhou using the topic questions she was given. ${ }^{2}$ This interview was conducted by a member of a cycling advocacy organization in Guangzhou.

\section{Process-Tracing: Empirical Findings}

\subsection{The Emergence and Evolution of Public Bicycle Programmes in Guangzhou}

Public bicycle programs have grown rapidly in China since the Hangzhou government (Zhejiang Province) introduced them from European cities. The public bicycle program in Hangzhou is operated by a state-owned enterprise. It received governmental investment and subsidies for both its initial construction and daily operation. It performs well, with more than 84,100 bicycles each being used for five trips per day [52].

This program has received both national and international acclaim. It is considered to be a successful case of new invitations for both sustainable transport and city branding by the government, the media, and the public. This is the fundamental reason that many cities' governments, especially those cities that enjoy similar political and economic status to Hangzhou, quickly acted to promote similar programs in their own cities. Some of them followed Hangzhou and funded state-owned companies to invest and operate the public bicycle program. Others gave policy support and/or financial support to private companies to allow them into the area. This is how market forces, especially private companies, can enter the field. Guangzhou is an interesting case for analyzing this issue, as it has various categories of public bicycle programs invested in and operated by different organizations. 
The Guangzhou government's public bicycle program emerged in 2010. To prepare for the 16th Asian Games, which were held in Guangzhou in November 2010, the Guangzhou government invested in a bus rapid transit (BRT) lane. A public bicycle program also received investment from the government as supporting facilities along the BRT lane. This program mirrored Hangzhou's, and a state-owned company (Guangzhou Public Bicycle Operation Management Company, Guangzhou, China. For more details, please refer to http: / / www.gsxt.gov.cn/\%7BDDBF08E7B59EA93546A9CFE497422B79966BA8DBF00 DD83B8CA7F51AE7DF41AEC835E003B49F5CC04D1F830EC-AB684397F82857E3765502974 73067F26935993532353235993532090E18232432350E33340F080F18231E191E25899E2DD4B D85DD6F1CC9A076104231F7CCF7E0DD5F9C008D4EB3DAA96F545354535453-1628053297 986\%7D, accessed 4 August 2021) was founded as a subsidiary corporation of the Guangzhou Transport Station Construction Management Centre, which was directly controlled by the Guangzhou Transportation Commission.

On 22 June 2016, 2000 bicycles in 18 stations along the BRT lane began to operate, later expanding to approximately 5000 bicycles in more than 100 stations [53]. The fee structure is as follows: $1 \mathrm{~h}$ of bicycle use is free for all users; 1 to $2 \mathrm{~h}$ costs RMB1 (approximately USD 0.15); 2 to $3 \mathrm{~h}$ costs RMB2; over $3 \mathrm{~h}$ costs RMB3 per hour; and the maximum cost per $24 \mathrm{~h}$ is RMB30 (For more information, please refer to http:/ / baike.baidu.com/view/3799544.htm, accessed 4 August 2021). Local residents can borrow bicycles using their bus or metro cards after registering and paying the deposit (RMB 300). All the bicycles, stations, and relevant facilities are funded by the government and operated by the state-owned company, which relies on a governmental subsidy for daily operation. As the main color of these bicycles is orange, the public refers to it as the "orange program" to distinguish it from other public bicycle programs. This name is also used to define this governmental program in the following analysis.

In addition to the orange program, two public bicycle programs emerged in Guangzhou in 2009 and 2010 - the yellow and red programs. The yellow program was invested in and operated by a private company, the Rising Sun Company, which came into existence in 2009 and was the first public bicycle company in Guangzhou. At that time, Guangzhou Metro Group Company Limited (Guangzhou, China) planned to provide public bicycles along some metro lines, especially in some metro stations, so it outsourced the project to the Rising Sun Company. Metro Group conducted the initial investment and construction. The Rising Sun Company (Guangzhou, China) was primarily responsible for daily operation and following investments. In 2009, 2000 yellow public bicycles in 29 stations started to operate, later increasing to 4800 bicycles and 50 stations [53].

The yellow bicycles are manual rentals rather than based on smart technical cards. Thus, the fee structure is similar to that of the orange program. However, the Rising Sun Company failed and left the public bicycle market in late 2013 and 2014. Its stations and bicycles were acquired by another private company, ToRide (Guangzhou, China), which provides green public bicycles. Therefore, the yellow bicycle program changed to the green program, consisting of over 2300 bicycles and 60 stations (GZ_04, 23 November 2015). The reasons for the Rising Sun Company's failure are explored in the next section.

The red program differs from the orange and the yellow-green programs, as it only operates in the Guangzhou Higher Education Mega Centre for university students and staff members rather than in central urban areas as the others do. It was totally invested in and operated by the Guangzhou University City Card Company Limited (Guangzhou, China) with no financial support from the government. In September 2010, 1000 red bicycles and 23 stations started to operate. The students and staff members of the universities and institutions in this area could then start using the red bicycles with their university cards. The fee structure of the red program is similar to those above. The red program, however, failed after 3 to 4 years of activity. By late 2014 and 2015, most of the red bicycles and their stations were abandoned, and in late 2015, they were replaced by the orange program, which has massively expanded all over the city since late 2015 . The following 
section focuses on exploring the extension of the orange program and the failure of both the yellow-green and red programs.

\subsection{The "Death" of Private Market Forces and the Extension of the State-Owned Programme}

From 2010 to 2015, four companies operated three public bicycle programs. One of them (the orange one) was governmentally founded and the other three (yellow-green and red ones) did not receive any financial support from the government. These companies are referred to as the first round of market force attempts. It was the first time that private market forces dealt with the utilitarian urban cycling issue in a way other than selling and repairing bicycles. They demonstrated the potential of market forces in providing and operating basic infrastructures, which is traditionally the government's responsibility. These market forces and their attempts, however, failed after several years of activity. The yellow program failed first, quitting the market in late 2013 and 2014. The green program, which replaced the yellow program, started to close its stations in central urban areas and shifted its focus to non-utilitarian cycling in non-urban areas in 2015 (Figures 1 and 2). The red program also failed and stopped operating in late 2014 and 2015.

The low-profit margin was the direct reason. In general, public bicycle companies that receive no financial support from the government can earn income from three main sources, as stated by the manager of the ToRide Company:

"The first is rental income- the income from renting bicycles and the loan interest of the deposit; the second is the revenue from advertising - in stations or on bicycles; and the third is the income from some services we provide in our stations, like selling newspapers, snacks and so on" (GZ_04, 23 November 2015).

The stair-step fee structure and the short-distance nature of urban cycling led to very low bicycle hire profits. For instance, in 2013, one of the public bicycle programs enjoyed more than 25,000 rides per day, but more than $90 \%$ were for free (The source of this information is a news report on an online news website New Economy, http:/ / www.xinjin gji.net/shangye/2374, accessed 2 May 2017. The link, however, is inaccessible in 2021. In order to ensure the authenticity of the information, we confirmed it to a respondent [GZ-04] who used to be the manager of one of the public bicycle enterprises in Guangzhou). They only earned approximately RMB100,000 from rentals, which is far short of the financial demand for daily operation and maintenance. Therefore, these companies had to develop other income resources and faced many problems in interacting with the government.

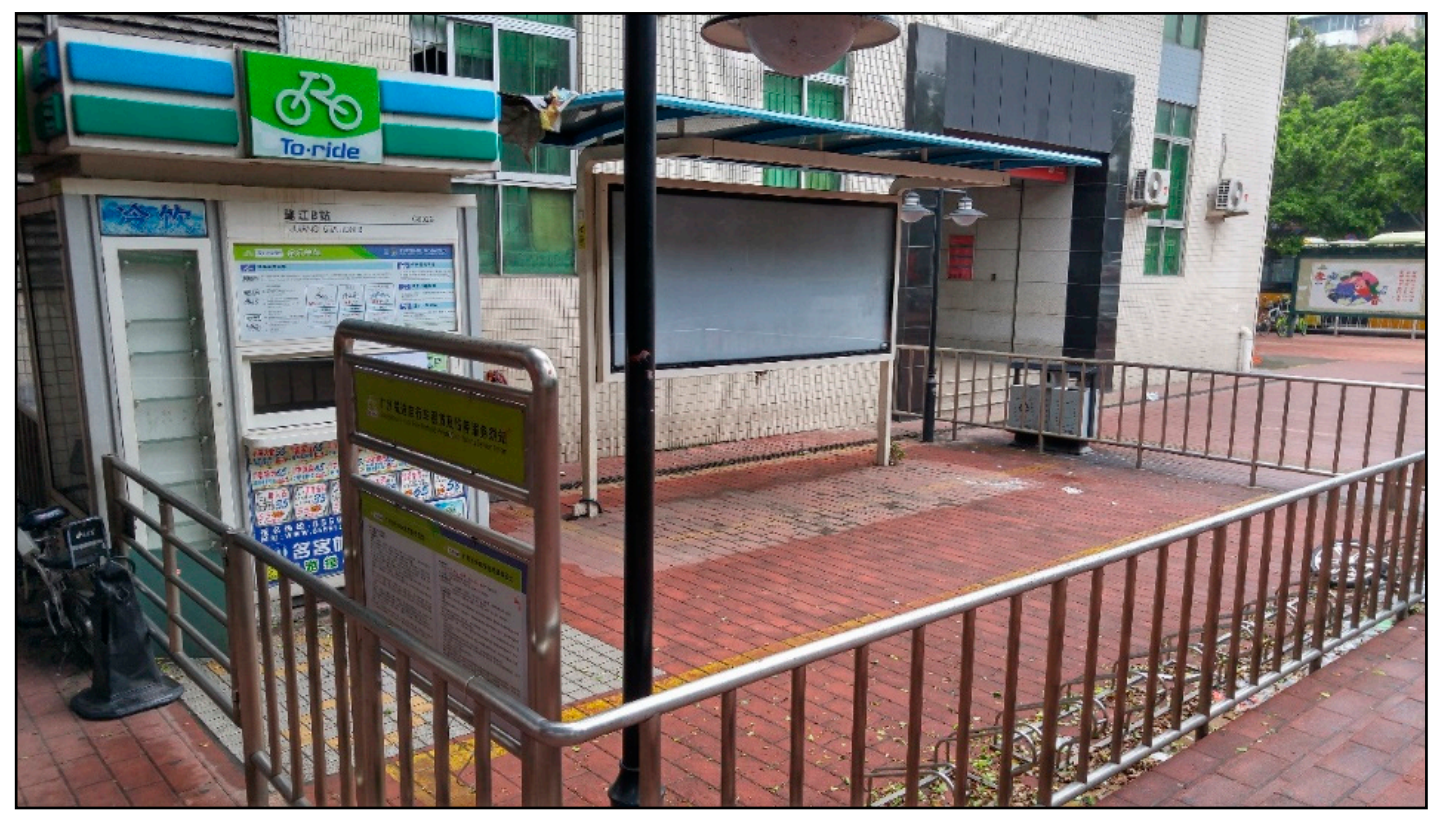

Figure 1. An Abandoned Public Bicycle Station in Guangzhou (this picture was taken by the first author on 31 January 2016). 


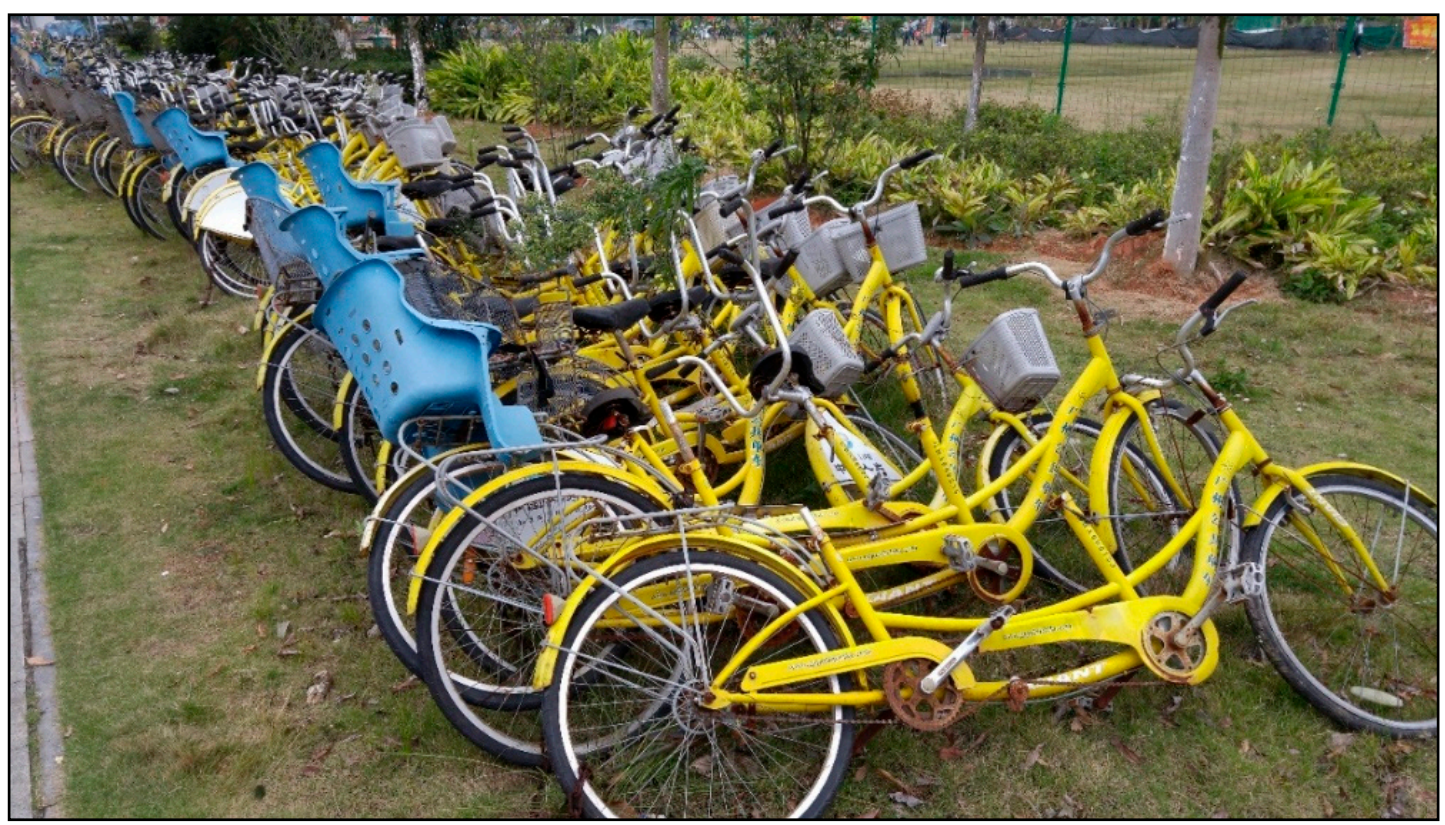

Figure 2. Abandoned Public Bicycles in Guangzhou (this picture was taken by the first author on 31 January 2016).

The first problem was various strict regulations and policies regarding the building and operating of stations. All these programs depended on the amount and locations of stations that are the nodes for renting and returning bicycles. Most potential income innovations were also based on the stations. Some companies wanted to conduct other business operations to increase their incomes, such as selling food, operating with banks to provide financial services, and receiving deliveries for local residents (GZ_04, 23 November 2015). However, they suffered many regulatory constraints in making such implementations. For instance, the manager of the yellow program once wanted to conduct retail business in their stations, and outlined the barriers to doing so in an interview with the media:

"It is very difficult. If we want to do it, we need to register in the business sector, but there are many problems. For instance, just the required information of house [address] numbers stumped me. The stations are on the roadside; they have no house numbers. But [the government] does not care-if you do not have one, you cannot apply for the license" [54].

The problems exceed the licensing issue. For example, if the stations wanted to expand or even maintain their business, they required basic resources, such as power and water. Companies faced different situations in different districts.

"To some extent, our destiny depends on the local government's attitude and actions. You know, these things are not big issues that have clear and strict rules, but in general, we face a relatively strict regulation from the government" (GZ_04, April 2015).

The above quote is also related to the second problem that the companies faced, even the government-funded one (the orange program) — strict governmental regulation of these companies' profitability means. This problem is rooted in the governmental orientation of the public nature of public bicycle programs, regardless of who the provider is. The government imposed strict regulations on the orange program's fee structure and advertising and basically forbade any other business service to guarantee the public nature of this program and "serve the public" (GZ_23, 19 November 2016). Therefore, as a market program, the orange program experienced heavy losses. The only reason that this program can keep operating is that the government funds it with approximately RMB20 million in subsidies per year (Xu, Wei, Luo, and Deng, 2015). However, the orange program still has financial difficulties (according to "inside information", from 2010 to 2013, the orange program met a loss of about 80 million RMB (GZ_04, 23 November 2015)) in daily operation and must rely on bank loans. 
The other programs had to follow the operational pattern of the orange program to serve the public if they wanted to secure governmental approval. This means they had to use similar fee structures and limited business sources, but with no governmental financial support. Therefore, it is understandable that these companies quickly concluded that they were unable to maintain daily operations. According to the rough estimate of a company manager, from 2009 (2010) to 2013, the yellow-green program lost approximately RMB30 million, and the red program lost a similar amount (GZ_04, 23 November 2015).

What made things worse for the programs with no governmental funding was that in June 2015, the government decided to extend the orange program from BRT line areas to other urban areas, including those covered by the green and red programs (at that time, the red program was nearly abandoned by the operating company). In the governmental budget adjustment in 2015, RMB120 million in financial aid was allocated to the Public Bicycle Project Promotion Fund. The goal of this fund is to provide 30,000 orange public bicycles in the urban area of Guangzhou, and the long-term vision is to provide 100,000 bicycles with further governmental financial support in the urban area to solve the "last mile" travel problem of the public (Xu et al., 2015). After that, the green program left the urban area and moved its focus to leisure cycling in non-urban areas, and the red bicycles were totally replaced by the orange program. Although the orange program has expanded rapidly, it relies on governmental investment and subsidies for both the initial construction and daily operation rather than achieving profits through market measures. To some extent, it is more of a government-affiliated agency than a market force.

Therefore, by the end of 2015, it seems that the market forces in the area of the public bicycle all failed and quit. Their failure indicates that market forces cannot work well in the utilitarian urban cycling field, which confirms governmental officials' claims that this field pertains to a public issue that "relies on the government" [55]. Things, however, do not end here. In the same year that the red program died, and the green program quit, another round of market force attempts with a new generation of public bicycles emerged in major cities in China, including Guangzhou.

\subsection{A New Round of Market Forces Based on Technological Innovation and the "Death" of the State-Owned Programme}

Starting in late 2015, along with the decrease of private providers in public bicycle programs in Guangzhou and across mainland China, a new round of market attempts in the utilitarian urban cycling field with a new generation of public bicycles occurred in some major Chinese cities. This new round is referred to as the second round of market force attempts. The major difference between the new programs and the old ones is that the new ones do not have bicycle stations, which were necessary for the latter (Figure 3). By adopting new information and Internet technology, users can unlock new public bicycles with their smartphones (There are various ways to lock and unlock new public bicycles with users' smartphones. For instance, some bicycles have QR codes. When users scan a code with a certain app, the bicycle is unlocked. In another category of bicycles, each has a unique number on it. A user can type this number into the app to have the secret key for the coded lock of this bicycle sent to the phone). That is why they are named "Smartphone-Based Sharing-Bicycles" to differentiate them from the first generation of public bicycles.

Therefore, the companies that operate SBSBs programs did not need to build stations and docks, but they did have to launch (helter-skelter) bicycles with GPS modules and information technical units in certain cities on roadsides and in public parking spaces. Then residents could use these bicycles by themselves. Users must install an app on their smartphones and deposit some money (usually approximately RMB300). They can then view all of the locations of available bicycles on the app and go to the nearest one. When the user finishes riding, he/she can leave the bicycle in any public area and lock it. The cost is automatically deducted from the money that the user pre-paid on his/her account linked to the app, and the bicycle is available for other users. 


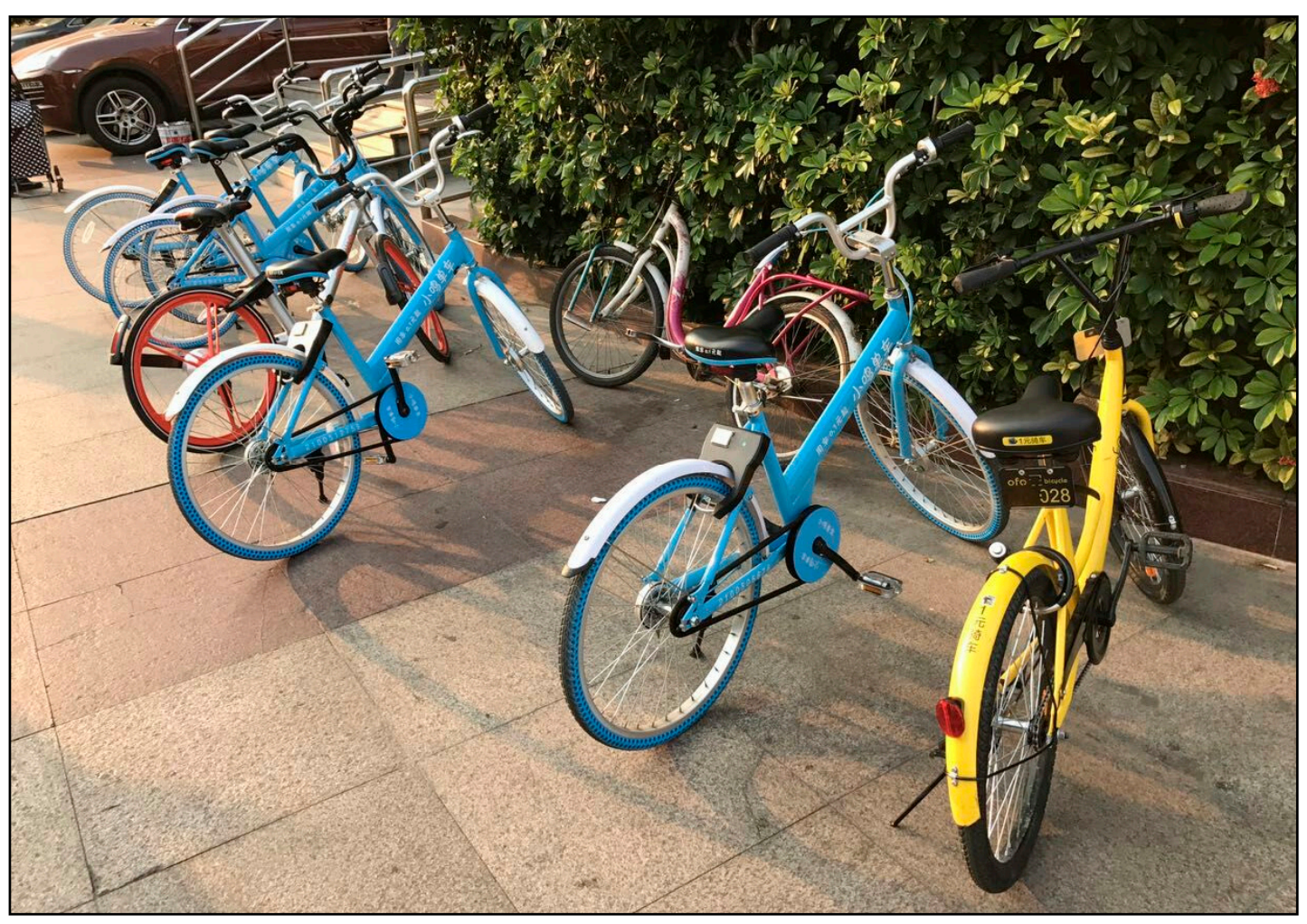

Figure 3. SBSBs in Guangzhou (this picture was taken by the first author on 11 February 2017).

As SBSBs do not depend on stations and docks, it enjoys several advantages for attracting investments and expanding. The most obvious one is that the cost of investing and operating greatly decreases, making the rate of return for this business higher than that of the first generation of private providers. More importantly, the companies that operate the new programs are subject to fewer administrative constraints. For these companies, the need to interact with the government is greatly reduced. Traditional governmental station-based constraints, such as land permission, water and electricity management, and advertising management, lost their foundation. Companies enjoy more freedom to operate their businesses.

In fact, if treated as a business model of bicycle rental, SBSBs are similar to public bicycles, not a business with huge profit margins. The price of SBSBs is a little higher compared with public bicycles. They also adopt a step-by-step charging model, and in general, the users need to pay 1 to $1.5 \mathrm{RMB}$ for the first 15 to 30 minutes ride, and 2 to 3 RMB for one hour's ride. This business needs to bear the production cost (about 300 to 1000 RMB for each bike)and operation cost (1000 RMB a year for each bike) of bicycles [56]. As there are some other sources of profit like the interest income from the deposit and advertising revenue, almost all the SBSBs companies cannot make ends meet. That is why almost all the SBSBs companies have been losing money all year round [57]. Nevertheless, what is different between public bicycles and SBSBs is that the latter is linked to and based on smartphones, which could collect personal and travel data. Moreover, as SBSBs are not station-based, the location of the bikes and citizens' travel by them are not fixed as the public bicycles. The "freedom" of the companies makes it possible to collect the "last kilometer" travel data, in other words, citizens' point-to-point travel data, which is regarded by Internet companies as of great commercial value [7]. As such, this business has attracted the attention of investors and grown quickly. In just 1 year, this business has attracted billions in investment and has emerged in several major cities in China (Tables 3 and 4$)$. 
Table 3. Four Major Chinese Cities' SBSBs Programmes ${ }^{1}$.

\begin{tabular}{|c|c|c|c|c|}
\hline & Beijing & Shanghai & Guangzhou & Shenzhen \\
\hline $\begin{array}{c}(2016) \\
\text { April-July }\end{array}$ & & Mobike & & \\
\hline August & Mobike & & & \\
\hline \multicolumn{5}{|l|}{ September } \\
\hline October & ofo Bike & $\begin{array}{c}\text { ofo Bike } \\
\text { Small Ming Bike }\end{array}$ & $\begin{array}{c}\text { Mobike } \\
\text { Small Ming Bike }\end{array}$ & Mobike \\
\hline November & Yi-Dai-Bu Bike & & ofo Bike & $\begin{array}{c}\text { ofo Bike } \\
\text { Small Ming Bike } \\
\text { Blue GOGO Bike }\end{array}$ \\
\hline December & & Youbike & $\begin{array}{l}\text { Blue GOGO } \\
\text { Bike; }\end{array}$ & \\
\hline
\end{tabular}

Table 4. Financing Rounds of Representative Chinese SBSBs Companies ${ }^{1}$.

\begin{tabular}{cccc}
\hline Company & Financing Rounds & Release Time & Financing Amount \\
& C2 & 10 October 2016 & USD130 million \\
& C1 & 26 September 2016 & Tens of millions of USD \\
ofo Bike & B & 2 September 2016 & RMB10 million \\
& A & RMB15 million & RMB9 million \\
& Pre-A & 1 February 2016 & Millions of RMB \\
& Angel round & 22 December 2015 & Over USD100 million \\
& C & 17 March 2015 & USD100 million \\
Mobike & B+ & 13 October 2016 & Tens of millions of USD \\
& B & Tens of millions of USD & Millions of USD \\
\hline A & A & 19 August 2016 & RMB100 million \\
& Angel round & 30 October 2015 & Tens of millions of RMB \\
\hline Youbike & Angel round & 8 October 2016 & Tens of millions of RMB
\end{tabular}

${ }^{1}$ The source: the information in this table is adopted from the on-line public report by Jinlicaijing on TMPOST, https://www.tmtpost.com/ 2538652.html, accessed on 4 August 2021. The table is made by the authours.

In September 2016, a company called Mobike entered Guangzhou after several months of operating in Shanghai and Beijing. Hundreds of bicycles were brought into the urban area of Guangzhou [53]. After the first round of launches, the company conducted several rounds of additions; by January 2017, there were nearly 90,000 Mobike bicycles in Guangzhou [58]. Following Mobike (Guangzhou, China), several other similar companies also emerged in Guangzhou, such as ofo Bike (Guangzhou, China), Small Ming Bike (Guangzhou, China), and bluegogo (Guangzhou, China). Each of them has launched or plans to launch thousands of public bicycles in the urban area of Guangzhou. The new generation of public bicycles is becoming a hot topic in Guangzhou's socio-political agenda.

For now (January 2019), these SBSBs companies are private and receive no financial support from the government. They have introduced new features compared to their failed predecessors. First, these companies expand on the meaning of bicycles and urban cycling in their advertisements. In contrast to the previous companies, which focused on describing bicycles as an environmentally friendly traffic mode, the new companies spend a great deal of effort connecting bicycles and cycling to broader meanings, such as "a modern lifestyle", "sharing economy" and "freedom" (For instance, please refer 
to some published interviews with the managers/founders of these companies: https: //www.xuexila.com/jieri/qingnianjie/3254806.html, accessed on 4 August 2021 (Mobike), http:/ / mt.sohu.com/20161212/n475646158.shtml, accessed on 4 August 2021 (ofo Bike) and http://tech.163.com/16/1214/07/C87RTK0V00097U7R.html, accessed on 4 August 2021 (bluegogo)). All these companies have announced that they are representing and popularising a fashionable and technical lifestyle rather than just renting bicycles. A sense of fashion is one of the most important elements in the design of bicycles (For instance, please refer to the advertisements posted on the websites of Mobike (http:/ /www.mobike .com/global/, accessed on 20 February 2017) and ofo (http:/ /www.ofo.so/\#/, accessed on 4 August 2021)). These companies want the public to know that riding their bicycles is chic and part of a fashionable lifestyle. This is in sharp contrast to the previous meanings, which only emphasized the efficiency and low cost of cycling. This kind of pro-cycling culture construction based on a fashionable lifestyle is similar to what Spinney and Lin explored in the production and economization of cycling culture in Taiwan [13] and also echoed with the cultural meaning added by ICT technologies to "green" transportation [11,12].

Secondly, the SBSBs companies enjoy closer relationships and frequent interactions with the public and civic cycling activists. As these companies have no stations or docks, there is a huge risk that the bicycles may be parked illegally, deliberately damaged, or even stolen. Therefore, these companies develop some kind of communication mechanism based on certain reward measures with the public. For instance, Mobike developed a hunter system by which users can report other users' illegal parking or destructive behavior. In so doing, the reporter is rewarded with credit points and the reported user loses his/her credit points. This user watch system helps companies enforce their rules, save maintenance costs, and increase their profits.

These companies also have close relationships with civic activists. Some managers were in fact pro-cycling civic activists before starting their businesses. For instance, the Guangzhou branch heads of Mobike, bluegogo, and ofo Bike are all personal friends of the leader of a cycling advocacy NGO in Guangzhou. After starting their businesses, they frequently interacted with this NGO and other relevant civic actors. These managers and their staff members attend the workshops and conferences organized by cycling activists, join online discussion groups of civic actors, and provide data to researchers. Civic actors also help these companies by discussing relevant issues online and offline, testing bicycles, providing suggestions, and publishing on their personal websites.

Thirdly, compared with the public bicycle companies, the SBSBs enjoy a different kind of relationship with the government. Unlike the first generation, which was either a regulatory object or semi-branch of the government, the newcomers are trying to be equal partners with the government in dealing with the cycling issue. This change and its potential occurred for two main reasons. Due to the disappearance of stations and docks, these companies suffer fewer administrative and regulative constraints. However, by getting investments from financial markets, they have many more economic resources than the previous generation, which is why they can support themselves on pure market measures rather than relying on governmental subsidies.

As time goes on, however, the SBSBs companies have started to face similar governmental regulations as the first-generation companies did. For instance, in August 2017, Guangzhou Municipal Transportation Commission informed all SBSBs companies in Guangzhou that they were not allowed to launch new bicycles in the city as there have been "too many" sharing bicycles in Guangzhou (For details, refer to http:/ / news.sina.com.cn /o/2017-08-03/doc-ifyitayr8906690.shtml, accessed 30 October 2017). However, compared with their "dead" predecessors, the SBSB companies seem to enjoy more freedom and power to bargain with the local government. For instance, although the launching of new bicycles is forbidden in principle, there are still new sharing bicycles emerging in Guangzhou (For instance, refer to http:/ / tech.163.com/17/1114/17/D37ITUPL00097U7R.html, accessed 16 November 2017). These companies also learned from the failure of the previous generation that they need governmental support, especially from local governments, to 
exist and grow. Therefore, at the beginning stage, they focused on the crowded and central areas of Guangzhou, where the government-funded public bicycle programs were relatively absent. By doing this, they avoided direct competition with the government-funded programs. They also tried to convince some local governments that supporting their businesses contributed to promoting urban cycling, consistent with the spirit of the central and provincial governments, without increasing public expenditure. They received some responses. For instance, in December 2016, Haizhu District's government announced it would cooperate with ofo Bike by lining up 1200 parking spaces for new public bicycles in its district [59].

Although the SBSB companies avoided direct competition with the state-owned public bicycle program, the fast extension of them still quickly brought the latter a huge shock. More and more users of the state-owned public bicycle program moved to SBSBs, which made the operating costs and account deficit increase. The state-owned operating firm tried several reform measures in 2017, like updating the facilities, and adjusting the prices and charging methods, etc. However, they produced very little effect. Eventually, this state-owned public bicycle program announced they would be stopping operations on the 15 October 2018, as "The (smartphone-based) sharing-bicycles in our city (Guangzhou) has better met the needs of citizens for their short distance travel" (For more details, refer to https://www.sohu.com/a/259656743_119778, accessed 4 August 2021).

\section{Discussion}

\subsection{The "Liberation" and Governance Challenge Brought by the Innovation}

Inter-field relations are a vital analytical dimension of the field approach [35,37]. However, how the development of the Internet and the technological innovations based on it have changed and created tension in the cycling field has hardly been investigated. This is an interesting and important dimension as during the transition process the relationship between various actors is also changed. Regarding the public sharing bicycles in Guangzhou, the governmental regulations and policies are guiding by two principlesland (and relevant infrastructures) control as the core of the governing logic, and the low-profit (semi-public-transit) mode positioning. This kind of governing logic directly leads to the lack of profitability of this business and transit it into a kind of public welfare that relied on public finance. Therefore, the failure of the market forces in this field is foreseeable.

Nevertheless, certain technological innovations in the Internet business field, such as the smartphone-based electronic lock, GPS, and electronic payment methods, liberate private companies in this field from the above governing logic (Figure 4). The SBSBs companies no longer need to apply to the government for land to construct settled stations and infrastructures. Instead, they use existing dispersive public parking spaces. Hence, the set of regulations/policies based on land control are not suitable for the SBSBs. The adopted innovations not only give the companies more freedom in their operations but also linked them to a wider economic capital market by giving financial investors more confidence in their expected economic and mobile data profits. With the support of the financial market, SBSBs companies have since become active semi-independent actors with increasing influence in the field.

These innovations and the new kind of business around them, however, may also have negative influences on the development of urban cycling. For instance, due to the profit-seeking nature of market forces, the absence of supervision, whether from the government or the public, naturally leads to cutthroat market competition among the involved companies [57]. Many problems in the business have emerged, such as the decline in bicycle quality for cost reduction [56], the excess launching of bicycles, and the lack of bicycle maintenance [18]. In addition, the excessive concern for the public bicycle business and the financial game around it also covers some other important issues related to a bicycle-friendly city [9], such as the lack of cycle tracks and parking spaces in 
certain areas [16], road-use regulations and awareness of traffic education for cyclists and motorists.

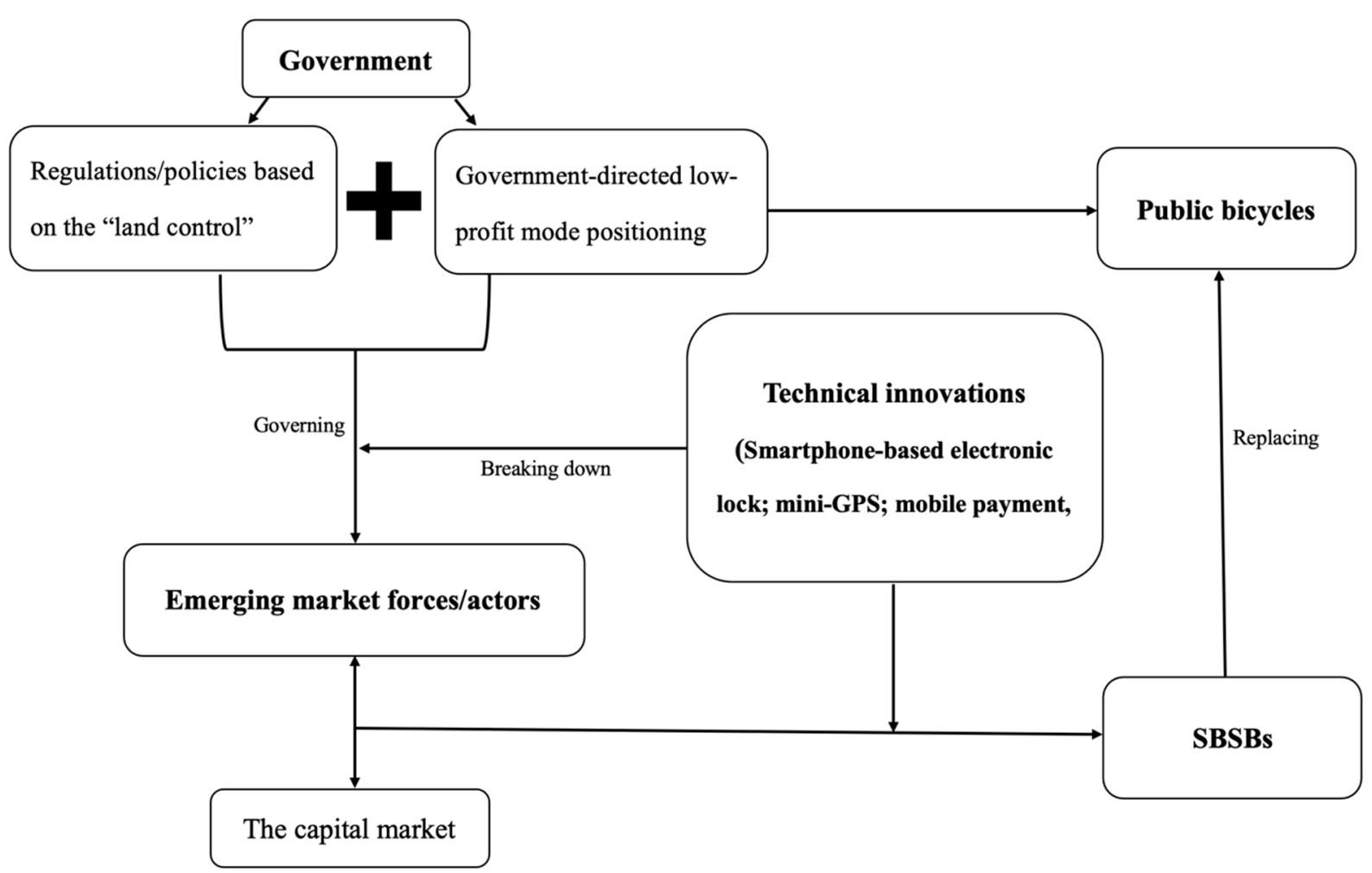

Figure 4. The basic framework of the relation between technical innovations and the governance challenge in the publicbicycle field.

\subsection{Capitals and Strategic Actions (Positions and Dispositions)}

The rapid development of the Internet economy in China, especially the smartphonebased economy, provides the soil for growth and a certain learning template for market forces in the cycling field. The success of business in smartphone-based shopping, meal ordering, and taxi booking services in recent years in China has given both entrepreneurs and investors the confidence to step into the cycling field. This tendency is combined with the foundation and market shortage for the utilitarian cycling business within the legacies of the previous periods. This is the basis for the quick growth of the engaging market forces in Guangzhou.

When directly engaging in the urban cycling field, market forces can cause changes in urban cycling and the relationships between different relevant actors regarding the cycling issue using their capital. In the Guangzhou case, the first-generation companies had relatively limited economic resources and relied largely on governmental regulations and policies. The new generation companies have benefitted from technological innovations and the development of the Internet economy, enabling them to get large investments from financial markets. To some extent, the first-generation companies can be considered as "dancers in shackles" (GZ_05, April 2015) as they were strictly governed and constrained by the government regarding their establishment, daily operations, and profit patterns. The SBSBs companies are gaining increasing independence, are less subject to government constraints, and are capable of conducting relatively independent actions with the huge economic resources they hold. This gives them the potential to become a new category of dominant actors in the future. Thus, shifting from dominated actors to active semiindependent actors is the foundation for engaging market forces to work as institutional entrepreneurs and bring real changes to the field. They also have more potential to run the urban cycling field than civic actors, the public, or the government. 
What kind of changes can the engaging market forces cause and how do they encourage others to accept these changes? The power of engaging market forces mainly comes from the economic resources they can accumulate and distribute, especially to address the above-mentioned shortage in the urban cycling system during the Cycling Reduction period. Therefore, providing bicycles with very low rent and investing in certain cycling infrastructures are the basic starting points of engaging market forces regardless of generation. From this point of view, the engaging market forces challenge the traditional dominant position of the government in Guangzhou, as providing economic resources on cycling issues was an important part of the foundation of the government's central and dominant position in the field. The first generation was an initial attempt, as the government strictly constrained its economic resources and methods of accumulating and distributing them. The new generation has found a way to connect with a wider financial market and is less constrained by regulations. Thus, it can invest much more money in providing huge numbers of low-rent bicycles, hiring celebrities for their advertisements, and organizing various events and public activities.

Through these endeavors, engaging private companies enhance influence in the cycling field while weakening the dominant governmental position. The media, the civic cycling activists, and the public all receive certain influences, directly or indirectly, on the understanding and vision of urban cycling in this city. To some extent, besides providing material bicycles and influences, the engaging market forces also fight for power to shape the social and cultural image of cycling in society, which was once reserved for the government. This explains the co-opting of cycling advocates into these companies, as the symbolic resources, social relationships, and public influences of the civic activists contributed to the promotion of these companies' vested interests and instrumental views of cycling.

\subsection{Discrepancies within the Field}

Compared to the emerging and dominated marginal actors, the existing and dominant central actor (the government) is more passive and insensitive to the potential influences brought by changes in relevant fields. This can be partially explained by its intention to maintain the current power structure and overall situation in the field. In contrast to the path-dependence literature [60,61], similar to historical sociology, which has indicated the self-reinforcing and reactive sequences in certain periods [62] this study highlights the tensions between the passive and insensitive dispositions of the government and nongovernmental actors' active and sensitive dispositions through their interactions. It also adds the significance of other relevant fields (e.g., technology) and actors (e.g., private companies) to explain the changes in the cycling field. Finally, the discrepancies between dispositions are not a result of the actors' agency alone but are rooted in and shaped by pre-existing circumstances and relational power structures.

In the initial phase, similar to the first generation of market attempts in Guangzhou, market forces maintain a good relationship and even collaborate with the government as a result of their relatively dominated and marginal position. Along with the extension of both market forces and civic actors, the basic divide between them will markedly widen. Their economic capital gives private companies the potential to achieve a semi-independent and even dominant position in the cycling field. They can even enjoy more power in influencing the government than civic cycling activists. The negative consequences of the expansion of private companies also attract some civic actors' worries, vigilance, and criticism. Thus, the government and civic actors are anticipated to react to the constantly expanding changes and tensions caused by market forces.

\section{Conclusions}

The issue of governing transformations within the socio-technical transition process has attracted quite a lot of scholars' attentions $[27,29,63]$. Regarding the daily mobility field, which is also a socio-technical system [1], how new technologies in the field of daily 
mobility/transportation impact existing modes of governance calls for more academic attention. Through a case study, this article explored how the adoption of new ICT-based technologies in the cycling field challenges the existing local mobility governance mode in urban China. By abandoning the need for fixed infrastructures and adding the capability to collect point-to-point travel data, the adopted technological innovations challenged the core of the governance system built for an existing transport mode and opening a governance gap. In this case, the time-lag between a new urban innovation and the corresponding governance $[17,64]$ is the result of the collapse of the original governance logic caused by the new technologies.

This kind of influence, however, is not linear or direct but is working out through a dynamic and interactive process. The relations, actions, and interactions between involved actors within the field, especially the government and market forces, are affected by the technological innovations and in return affect the socio-technical transition process. Within the singular Chinese political and urban context, the implantation of technological innovations contributes to liberating involved private companies from various and strict governmental regulations, which improved investors' confidence in these companies. Based on this huge source of accumulated economic capital, the market forces managed to navigate a transition from "dominant actors" to "active semi-independent actors" in the cycling field. Consequently, the second generation of private companies-SBSBs companies-enjoyed fewer government regulations and even more economic resources in advancing the business model by not only providing bicycles and exerting political influence but also by reshaping the social and cultural meaning of cycling through advertising and reports. Activities that once were government responsibilities were now conducted by private companies, which challenged the government's dominant position in the hierarchical power structure of utilitarian cycling.

The findings of this article highlight the importance of analyzing the social and political attributes of new technologies/devices/innovations in the daily mobility field [12,65]. When travel patterns change, the existing governance faces a challenge and needs to be adjusted or rebuilt accordingly. The key point is to adopt a relational analytical approach and treat the new technology as an element with social impact, rather than only the outcome of certain changes. These findings provide the academia and the managers with implications for understanding the impact of innovations on achieving sustainable mobility. Besides studying cycling, this article can also contribute some insights to other relevant areas like online car-hailing governance, smart transportation development, and new energy vehicle governance. As this study mainly focused on the changing process from public bicycles to SBSBs, it certainly has the limitation that we do not track what has happened to SBSBs after they replaced the former. The story does not end here, there are continuous new changes emerging in this field, like enterprise competition and elimination, new governmental management measures, different SBSBs development patterns in various cities, etc. Besides, due to the data limitation and limited scope of discussion, this article is not connected to some other related daily travel modes, like private bicycles and e-scooters/motorbikes. They, together with sharing bicycles, constitute the transitions of urban daily mobility. All the issues can be the concern of future research.

Author Contributions: Conceptualization, H.T. and S.D.; methodology, H.T.; writing—original draft preparation, H.T.; writing-review and editing, H.T. and S.D. All authors have read and agreed to the published version of the manuscript.

Funding: This work has been supported by the National Social Science Foundation of China (Grant No. 20CSH045).

Institutional Review Board Statement: Not applicable.

Informed Consent Statement: Not applicable.

Conflicts of Interest: The authors declare no conflict of interest. 


\section{References}

1. Geels, F.W.; Kemp, R.; Dudley, G.; Lyons, G. Automobility in Transition? A Socio-Technical Analysis of Sustainable Transport; Routledge: New York, NY, USA, 2011.

2. Winters, M.; Buehler, R.; Götschi, T. Policies to Promote Active Travel: Evidence from Reviews of the Literature. Curr. Environ. Health Rep. 2017, 4, 278-285. [CrossRef]

3. Pucher, J.; Buehler, R.; Seinen, M. Bicycling renaissance in North America? An update and re-appraisal of cycling trends and policies. Transp. Res. Part A Policy Pract. 2011, 45, 451-475. [CrossRef]

4. Markard, J.; Raven, R.; Truffer, B. Sustainability transitions: An emerging field of research and its prospects. Res. Policy 2012, 41, 955-967. [CrossRef]

5. Yang, R.O. Political Process and Widespread Protests in China: The 2010 labor protest. J. Contemp. China 2015, $24,21-42$. [CrossRef]

6. Tan, H.; Martínez López, M.A. Dancing with shackles? The sociopolitical opportunities, achievements, and dilemmas of cycling activism in Guangzhou, China. J. Urban Aff. 2019, 42, 241-256. [CrossRef]

7. Shengshihuayan Business Management. Research Report on Market and Competitive Development Trend of China's Public Bicycle Industry from 2019 to 2025. Available online: https:/ /www.chyxx.com/research/201906/751400.html (accessed on 3 August 2021). (In Chinese)

8. Luo, W. Ministry of Transport: More than 360 Cities Have Shaing-Bicycles Programs, and the Average Daily Order Volume Exceeds 45.7 Million. Available online: https:/ /cn.chinadaily.com.cn/a/202010/22/WS5f9150c2a3101e7ce972ac33.html (accessed on 3 August 2021). (In Chinese)

9. Shi, J.G.; Si, H.; Wu, G.; Su, Y.; Lan, J. Critical factors to achieve dockless bike-sharing sustainability in China: A stakeholderoriented network perspective. Sustainability 2018, 10, 2090. [CrossRef]

10. Shen, Y.; Zhang, X.; Zhao, J. The Mobility Patterns of Dockless Bike Sharing: A Four-month Study in. Transp. Res. Part D 2020, 98 , 102961. [CrossRef]

11. Ploeger, J.; Oldenziel, R. The sociotechnical roots of smart mobility: Bike sharing since 1965. J. Transp. Hist. 2020, 41, 134-159. [CrossRef]

12. Curran, D.; Tyfield, D. Low-Carbon Transition as Vehicle of New Inequalities? Risk-Class, the Chinese Middle-Class and the Moral Economy of Misrecognition. Theory Cult. Soc. 2020, 37, 131-156. [CrossRef]

13. Spinney, J.; Lin, W.I. (Mobility) Fixing the Taiwanese bicycle industry: The production and economisation of cycling culture in pursuit of accumulation. Mobilities 2019, 14, 524-544. [CrossRef]

14. Caulfield, B.; O’Mahony, M.; Brazil, W.; Weldon, P. Examining usage patterns of a bike-sharing scheme in a medium sized city. Transp. Res. Part A Policy Pract. 2017, 100, 152-161. [CrossRef]

15. Spinney, J. Fixing mobility in the neoliberal city: Cycling policy and practice in London as a mode of political-economic and biopolitical governance. Ann. Am. Assoc. Geogr. 2016, 106, 450-458. [CrossRef]

16. Guo, T.Y.; Zhang, P.; Shao, F.; Liu, Y.S. Allocation optimization of bicycle-sharing stations at scenic spots. J. Cent. South Univ. 2014, 21, 3396-3403. [CrossRef]

17. Lin, W.I.; Spinney, J. Mobilising the dispositive: Exploring the role of dockless public bike sharing in transforming urban governance in Shanghai. Urban Stud. 2021, 58, 2095-2116. [CrossRef]

18. Spinney, J.; Lin, W.-I. Are you being shared? Mobility, data and social relations in Shanghai's Public Bike Sharing 2.0 sector. Appl. Mobil. 2018, 3, 66-83. [CrossRef]

19. Laszlo, A. Leadership and systemic innovation: Socio-technical systems, ecological systems, and evolutionary systems design. Int. Rev. Sociol. 2018, 28, 380-391. [CrossRef]

20. Van der Merwe, S.E.; Biggs, R.; Preiser, R. A framework for conceptualizing and assessing the resilience of essential services produced by socio-technical systems. Ecol. Soc. 2018, 23, 12. [CrossRef]

21. Fuenfschilling, L.; Binz, C. Global socio-technical regimes. Res. Policy 2018, 47, 735-749. [CrossRef]

22. Sony, M.; Naik, S. Industry 4.0 integration with socio-technical systems theory: A systematic review and proposed theoretical model. Technol. Soc. 2020, 61, 101248. [CrossRef]

23. Magro, E.; Wilson, J.R. Policy-mix evaluation: Governance challenges from new place-based innovation policies. Res. Policy 2019, 48, 103612. [CrossRef]

24. Kuhlmann, S.; Stegmaier, P.; Konrad, K. The tentative governance of emerging science and technology-A conceptual introduction. Res. Policy 2019, 48, 1091-1097. [CrossRef]

25. Simmons, G.; Giraldo, J.E.D.; Truong, Y.; Palmer, M. Uncovering the link between governance as an innovation process and socio-economic regime transition in cities. Res. Policy 2018, 47, 241-251. [CrossRef]

26. Nill, J.; Kemp, R. Evolutionary approaches for sustainable innovation policies: From niche to paradigm? Res. Policy 2009, 38, 668-680. [CrossRef]

27. Markard, J.; Suter, M.; Ingold, K. Socio-technical transitions and policy change-Advocacy coalitions in Swiss energy policy. Environ. Innov. Soc. Transit. 2016, 18, 215-237. [CrossRef]

28. Fuenfschilling, L.; Truffer, B. The interplay of institutions, actors and technologies in socio-technical systems-An analysis of transformations in the Australian urban water sector. Technol. Forecast. Soc. Chang. 2016, 103, 298-312. [CrossRef] 
29. Edmondson, D.L.; Kern, F.; Rogge, K.S. The co-evolution of policy mixes and socio-technical systems: Towards a conceptual framework of policy mix feedback in sustainability transitions. Res. Policy 2019, 48, 103555. [CrossRef]

30. Rosenbloom, D. A clash of socio-technical systems: Exploring actor interactions around electrification and electricity trade in unfolding low-carbon pathways for Ontario. Energy Res. Soc. Sci. 2019, 49, 219-232. [CrossRef]

31. Weber, M.; Rohracher, H. Legitimizing research, technology and innovation policies for transformative change. Res. Policy 2012, 41, 1037-1047. [CrossRef]

32. Boon, W.P.C.; Bakker, S. Learning to shield-Policy learning in socio-technical transitions. Environ. Innov. Soc. Transit. 2016, 18, 181-200. [CrossRef]

33. Musiolik, J.; Markard, J. Creating and shaping innovation systems: Formal networks in the innovation system for stationary fuel cells in Germany. Energy Policy 2011, 39, 1909-1922. [CrossRef]

34. Wacquant, L.J.D. Towards A Reflexive Sociology: A workshop with Pierre Bourdieu. Sociol. Theory 1989, 7, 26-63. [CrossRef]

35. Bourdieu, P.; Wacquant, L. Invitation to a Reflexive Sociology; University of Chicago Press: Chicago, IL, USA, 1992.

36. Bourdieu, P. Social Space and Symbolic Power. Sociol. Theory 1989, 7, 14-25. [CrossRef]

37. Townley, B. Bourdieu and Organizational Theory: A Ghostly Apparition? In The Oxford Handbook of Sociology, Social Theory, and Organization Studies; Adler, P., Gay, P.D., Morgan, G., Reed, M., Eds.; Oxford University Press: Oxford, UK, 2014 ; pp. 39-63.

38. Krause, M. How fields vary. Br. J. Sociol. 2018, 69, 3-22. [CrossRef] [PubMed]

39. Hess, D.J.; Frickel, S. Introduction: Fields of Knowledge and Theory Traditions in the Sociology of Science; Emerald Group Publishing Limited: Bingley, UK, 2014; ISBN 9781783506682.

40. Fahmy, N.; Attia, M.A. majeed A Field Study of Arab Data Journalism Practices in the Digital Era. J. Pract. 2021, 15, 170-191. [CrossRef]

41. Leschziner, V. At the Chef's Table: Culinary Creativity in Elite Restaurants; Stanford University Press: Stanford, CA, USA, 2015.

42. Zhang, Y.; Mi, Z. Environmental benefits of bike sharing: A big data-based analysis. Appl. Energy 2018, 220, 296-301. [CrossRef]

43. Huré, M.; Passalacqua, A. La Rochelle, France, \& the invention of bike sharing public policy in the 1970s. J. Transp. Hist. 2017, 38, 106-123. [CrossRef]

44. Jiang, N. The role of the government in the sharing economy era: The case of sharing bicycles. Hebei Acad. J. 2017, 37, 138-142. (In Chinese)

45. Peng, G.; Xiangzhi, L.; Yi, H.; Tu, S.; Bai, X.; Yang, Y.; Ye, L. Bike Sharing: Collaborative Governance in Internet Technology and Public Services. J. Public Manag. 2017, 14, 1-10. (In Chinese)

46. Yang, Z.; Dong, K.; Xuemei, Z. A Review of Research on Bicycle-sharing in China and Foreign Countries. J. Chengdu Univ. Soc. Sci. 2018, 27-33. (In Chinese)

47. SCPSR (State Commission for Public Sector Reform). About the Opinions on Some Issues of Deputy Provincial City. Available online: http:/ / www.reformdata.org/index.do?m=wap\&a=show\&catid=418\&typeid=\&id=23941 (accessed on 20 December 2016). (In Chinese)

48. Statistics Bureau of Guangzhou Population Scope and Distribution in Guangzhou in 2015. Available online: http://www.gzstats. gov.cn/tjyw/201604/t20160412_39495.htm (accessed on 20 December 2016). (In Chinese)

49. Tan, H. The Politics of Urban Cycling Mobility: An Analysis of the Social and Political Change in Hong Kong and Guangzhou. Ph.D. Thesis, City University of Hong Kong, Hong Kong, China, 2017.

50. Taylor, S.J.; Bogdan, R. Introduction to Qualitative Research Methods: A Guidebook and Resource, 3rd ed.; Wiley: New York, NY, USA, 1998.

51. Kuckartz, U. Qualitative Text Analysis; Sage Publications: London, UK, 2014.

52. Bike Sharing: Hangzhou. Available online: http://www.publicbike.net/en/c/city.aspx?c=Hangzhou (accessed on 18 February 2017).

53. Meddin, R. The Bike-Sharing World Map. Available online: www.bikesharingmap.com (accessed on 18 February 2017).

54. Qi, B. Guangzhou Public Bicycle Enterprise Overall Losses. Available online: http:/ / www.xinjingji.net/shangye/2374 (accessed on 10 February 2017).

55. Meiqi-Biketo Guangzhou Invests 120 Million Yuan in Promoting Public Bicycles. Available online: https://www.sohu.com/a/2 0099108_115730 (accessed on 4 August 2021). (In Chinese)

56. Dalicaijing What is the Cost of Sharing a Bike? Available online: https:/ / www.sohu.com/a/198364718_211762 (accessed on 4 August 2021). (In Chinese)

57. Cai, S. If the Price Rises, Can It Make Shared Bicycles Profitable? Available online: http://capital.people.com.cn/n1/2019/0805 / c405954-31275299.html (accessed on 4 August 2021). (In Chinese)

58. Meiqi-Biketo Where Will Guangzhou Public Bicycles Go? Available online: https://www.sohu.com/a/124300323_115730 (accessed on 4 August 2021).

59. Zhu, R. Mobile Goes into Another City. Available online: http://www.qdaily.com/articles/35340.html (accessed on 18 February 2017).

60. Isaac, L.W. Transforming Localities: Reflections on Time, Causality, and Narrative in Contemporary Historical Sociology. Hist. Methods A J. Quant. Interdiscip. Hist. 1997, 30, 4-12. [CrossRef]

61. Sewell, W.H. Three Temporalities: Toward an Eventful Sociology. In The Historic Turn in the Human Sciences; McDonald, T.J., Ed.; University of Michigan Press: Ann Arbor, MI, USA, 1996; pp. 245-280. 
62. Mahoney, J. Path Dependence in Historical Sociology. Theory Soc. 2000, 29, 507-548. [CrossRef]

63. Borrás, S.; Edler, J. The roles of the state in the governance of socio-technical systems' transformation. Res. Policy $2020,49,103971$. [CrossRef]

64. Yoon, J.W.; Pinelli, F.; Calabrese, F. Cityride: A predictive bike sharing journey advisor. In Proceedings of the 2012 IEEE 13 th International Conference on Mobile Data Management, Bengaluru, India, 23-26 July 2012; pp. 306-311. [CrossRef]

65. Zuev, D.; Tyfield, D.; Urry, J. Where is the politics? E-bike mobility in urban China and civilizational government. Environ. Innov. Soc. Transit. 2019, 30, 19-32. [CrossRef] 